\title{
Research Projects on Materials and Devices Published in 2007 by Members of the Japan Prosthodontic Society
}

Ikufumi Kurasawa, DDS, PhD

Department of Oral and Maxillofacial Biology, Graduate School of Oral Medicine, Matsumoto Dental University, Shiojiri, Japan

Key words: titanium castings, shade guides, zirconia, implant

\section{Introduction}

This article reviews the findings of original $\mathrm{pa}^{-}$ pers in the area of materials and devices published in the Journal of the Japan Prosthodontic Society (J Jnp Prosthodontic Soc: Nippon Hotetsu Shika Gakkai Zasshi in the Medline/PubMed) published in Volume 51, 2007. A total of five articles related to prosthodontic materials, devices and implant prosthesis were picked up and the contents were summarized.

\section{Polishing titanium}

Titanium was introduced in the 1970 s for cast dental applications and became popular in the 1980s for crowns and removable partial dentures (RPDs). ${ }^{1}$ However, technical shortcomings, such as the increased difficulty of grinding and polishing procedures with conventional chair-side and laboratory instruments restricted the use of titanium in dental practice. ${ }^{2,3}$ More recently, newer grinding techniques have been introduced. ${ }^{4}$ Then, Miura et $\mathrm{al}^{5}$ investigated the surface properties of titanium castings, polished using their method of polishing titanium on both the mirror and inner surfaces (Fig. 1). In this study, the casting surface of pure titanium was polished using two methods: a conventional procedure for mirror surfaces and a modified procedure consisting of minimal grinding for acceptable fit of

Corresponding to: Dr Ikufumi Kurasawa

Department of Oral and Maxillofacial Biology, Graduate School of Oral Medicine, Matsumoto Dental University 1780 Gobara Hirooka, Shiojiri, Nagano 399-0781, Japan Tel: +81-263-51-2265, Fax: +81-263-51-2265

E-mail: kurasawa@po.mdu.ac.jp the inner surface. To evaluate the polishing surface, the center line average roughness (Ra) was measured. Then, qualitative analysis and map analysis were performed using Electron Probe $\mathrm{X}$-ray Microanalysis, and casting $\mathrm{Au}-\mathrm{Pt}$ alloy and $\mathrm{Co}-\mathrm{Cr}$ alloy specimens were used as controls. The Ra on the titanium inner surface was $1.52 \mu \mathrm{m}$, which was approximately four times higher than that on the mirror surface $(0.37 \mu \mathrm{m})$, and approximately two times higher than that for the $\mathrm{Au}^{-}$ $\mathrm{Pt}$ and $\mathrm{Co}-\mathrm{Cr}$ alloys. Qualitative analysis of the titanium mirror surface revealed elements such as $\mathrm{C}, \mathrm{Si}$, and $\mathrm{Al}$, as well as the ingot elements. In addition, $\mathrm{P}$ was also detected on the titanium inner surface. From a practical viewpoint, they reported that the mirror and inner surfaces formed by their polishing method for titanium yielded permissible roughness. However, a reaction layer and elements derived from the investment material remained on the titanium inner surface.

\section{Incisal edges of natural teeth and shade tabs}

Traditionally, dentists select shades for restorations by matching the color of the natural teeth with shade tabs from a manufacturer's shade guide. ${ }^{6}$ However, these shade guides have numerous limitations, and the characteristics of natural teeth make shade selection difficult. For example, the range of shades in shade guides are not consistent with those of the incisal edges of the natural teeth. Ishioka et $\mathrm{al}^{7}$ analyzed the optical properties of the incisal edges of natural teeth and compared them with those of the dental ceramic system in terms of the translucency and shade of color. A multi-spectra camera system (MSC-2000) was used for measuring and calculating the $\mathrm{L}^{*}, \mathrm{a}^{*}, \mathrm{~b}^{*}, \mathrm{C}^{*}$, and the translucency parameter (TP). The incisal edge areas of 175 natural teeth and 66 types of shade tabs 


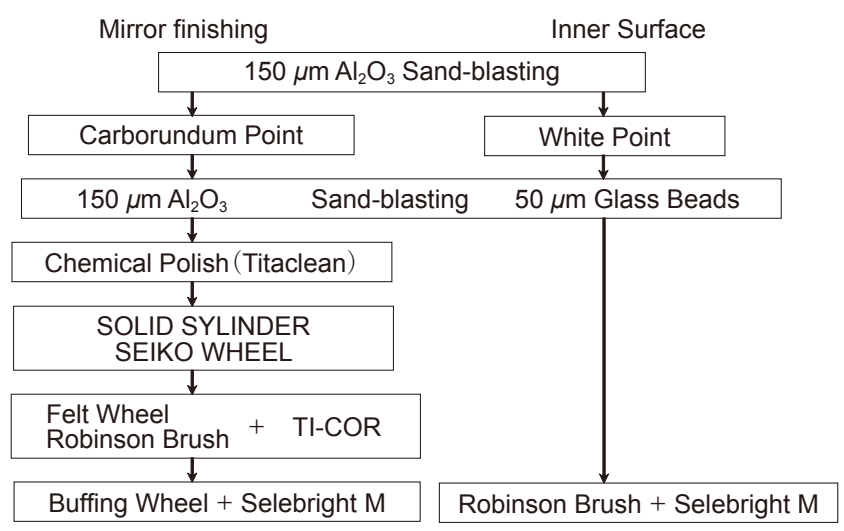

Fig. 1 Polishing methods of titanium castings. ${ }^{5)}$

from 3 types of shade guides, and 25 incisal ceramic samples selected from 4 types of ceramics were compared against a black background and a white background. In regard to the incisal edges of the natural teeth, the values of $\mathrm{L}^{*}$ were lower than those of the shade guides, and the values of $\mathrm{C}^{*}$ were lower than those of the incisal ceramics. The values for $\mathrm{a}^{*}$ and $\mathrm{b}^{*}$ for the shade guides and incisal ceramics were distributed in a narrow range as compared with those of the incisal edges of the natural teeth. No correlations were noted between the TP and $L^{*}, a^{*}$ or $b^{*}$ values for either the incisal edges of the natural teeth or the shade guides. While there were correlations between the TP and $\mathrm{L}^{*}$ values for the incisal ceramics, no correlations were noted between the TP and $\mathrm{a}^{*}$ or $b^{*}$ values. To summarize, the shade of color of the incisal edges of the natural teeth was widely distributed in terms of both brightness and chroma, and the translucency of each shade tab was greater than that of the incisal edges of the natural teeth. In both the incisal edges of the natural teeth and the shade tabs, the translucency and hue were mutually independent factors. Therefore, it was noted that a computer color-matching system $^{8}$ using incisal color shade tabs may be needed for shade selection in the future.

\section{Adhesion of resin cement to zirconia}

To enhance the bond strength of the luting cements to the ceramic surface, a number of techniques have been reported which mechanically facilitate resin-ceramic bonding. Zirconia ceramics cannot be roughened by hydrofluoric acid etching, since such ceramics do not contain a silicon dioxide (silica) phase. For this reason, special conditioning systems are indicated for this type of ceramics. ${ }^{9}$ Two types of resin cements exist: conventional BisGMA-based resin cements and the so-called adhesive resin cements that contain functional monomers such as MDP (10-methacryloyloxydecyl dihydrogen phosphate). ${ }^{10}$ Murahara et $\mathrm{al}^{11}$ investigated the effects of silanation and the adhesive monomer, MDP, on the bonding durability of the resin cement to zirconia. They prepared two sizes of zirconia disks whose bonding surfaces were air-particle-abraded with $\mathrm{Al}_{2} \mathrm{O}_{3}$, and then bonded with MDP-containing or non-MDP-containing cements to fabricate test specimens. They used the thermo-cycle test to analyze the shear bond strengths of the test specimens in each group. For test groups without silanation, the specimens bonded with MDP-containing resin cement showed significantly higher bond strength. In contrast, bonding with nonMDP-containing resin cements failed during the thermo-cycling process. For the silanated groups, the specimens pre-treated with MDP-containing silane coupling agent and bonded with non-MDPcontaining resin cement exhibited the highest shear bond strength, followed by that of the specimens pre-treated with the MDP-containing silane coupling agent and bonded with MDP-containing resin cement. In contrast, all specimens pre-treated with non-MDP-containing silane coupling agent bonded with the non-MDP-containing resin cements failed during the thermo-cycling process. They conclude that within the limitations of this study, the MDP adhesion monomer was effective in improving the bond durability of the resin cement to zirconia.

\section{Layering porcelains}

Ceramic materials used for the fabrication of a ceramic restoration are fired up to the sintering temperature and air-cooled after reaching this temperature. During cooling, substantial stress formation may occur and cause immediate cracking of porcelain, or an increase in the probability of fracture of the restoration. Thermal incompatibility between veneering porcelain and a metal substrate is often characterized by differences in their thermal expansion coefficient values. ${ }^{12}$ Miura et $\mathrm{al}^{13}$ investigated the coefficients of thermal expansion and shrinkage of an all-ceramic system (Cercon smart ceramics, DeguDent) utilizing tetragonal stabilized zirconia. The coef- 
ficients of thermal expansion and shrinkage of the core material and the layering porcelains (dentin and enamel) used in their study were measured according to the ISO 9693 standard. The core material and layering porcelain were tested. They evaluated the coefficients of thermal expansion and shrinkage using a push-rod dilatometer at a heating rate of $5^{\circ} \mathrm{C} / \mathrm{min}$ over a temperature range of $25^{-} 700^{\circ} \mathrm{C}$ for the core, and $25-550^{\circ} \mathrm{C}$ for the layering porcelain. The coefficients of thermal expansion were determined to be between 25 and $500^{\circ} \mathrm{C}$ from the plotted curve of expansion versus temperature. For the core material, the coefficients of thermal expansion and shrinkage showed almost the same value $\left(10.8 \times 10^{-6} /{ }^{\circ} \mathrm{C}\right)$. For the layering porcelains, the coefficients of thermal expansion and shrinkage

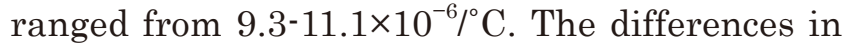
the coefficients of thermal expansion and shrinkage between the core material and the layering porcelains were $-0.3-1.5 \times 10^{-6} /{ }^{\circ} \mathrm{C}$. They concluded that the core material and layering porcelains using this study are suitably matched.

\section{Finite element analysis of implants}

Several studies have shown that ankylotic or osseointegrated post-shaped implants had onetenth the mobility of natural teeth under axial and horizontal loads. ${ }^{14}$ Natural teeth can adapt to deformations and torsions because of their periodontal mobility, whereas ankylotic implants cannot. ${ }^{15}$ Although several studies have conducted model analysis for stress distribution in the surrounding bone of implants, few experimental studies have analyzed the relation between occlusion and implant prosthesis. Maezawa et $\mathrm{al}^{16}$ investigated the influence of the intensity of occlusal contact or occlusal height of an implantretained restoration on the stress in the crown surface and supporting bone. They created twodimentional finite element models: 1 . the maxillary and mandibular first molars with supporting periodontal structures (Model-M-M). 2. One of the molars replaced by a restoration retained by a thread-type implant (Model I-M: implant in the maxilla, Model M-I: implant in the mandible). Interestingly, they adopted the models in which the periodontal ligament with a force was simulated by the vertical displacement of the mandible up to $0.24 \mathrm{~mm}$ from the initial occlusal contact. Nonlinear contact analysis was conducted to calcu- late the stress in both the restoration and the supporting tissues. To obtain a restoration that shows the same stress in the occlusal surface as that in the natural molars under the maximum bite force, the occlusal heights in Model I-M and M-I needed to be reduced by $0.10 \mathrm{~mm}$ and 0.11 $\mathrm{mm}$, respectively. The restorations were not expected to occlude with their natural molar antagonists under a bite force of lower than $13.0 \%$ and $15.8 \%$ of the maximum force, respectively. Thus, they suggested the following: reduction in the intensity of the occlusal contact, or decreased occlusal height of an implant-retained single restoration, allows the establishment of an equivalent occlusal stress with the natural molars under the maximum bite force. This adjustment, either during fabrication or the try-in procedure, can suppress the excessive stress that may be created in the tissues. With this procedure, however, the restoration does not make contact with the antagonistic tooth under relatively low bite forces.

\section{References}

1. Parr GR, Gardner LK, Toth RW. Titanium: the mystery metal of implant dentistry. Dental materials aspects. J Prosthet Dent 1985; 54: 410-414.

2. Cunningham DM. Comparison of base metal alloys and type IV gold alloys for removable partial denture frameworks. Dent Clin North Am 1973; 17: 719-722.

3. Dharmar S, Rathnasamy RJ, Swaminathan TN. Radiographic and metallographic evaluation of porosity defects grain structure of cast chromium cobalt removable partial dentures. J Prosthet Dent 1993; 69: 369-373.

4. Kawai Y, Takayama Y, Abe M et al. Study of polishing steps for titanium castings. Tsurumi Univ Dent J 1997; 23: 407-418.

5. Miura E, Takayama Y, Kawai Y et al. Analysis of polished surfaces of titanium castings. J Jpn Prosthodont Soc 2007; 51: 11-21.

6. Curd FM, Jasinevicius TR, Graves A et al. Comparison of the shade matching ability of dental students using two light sources. J Prosthet Dent 2006; 96: 391-396.

7. Ishioka M, Sakashita K. Analysis of the optical observation of incisal edges of natural teeth and shade tabs. J Jpn Prosthodont Soc 2007; 51: 49-57.

8. Ishikawa-Nagai S, Ishibashi K, Tsuruta $\mathrm{O}$ et al. Reproducibility of tooth color gradation using a computer color-matching technique applied to ceramic restorations. J Prosthet Dent 2005; 93: 129-37.

9. Özcan M, Vallittu PK. Effect of surface condition- 
ing methods on the bond strength of luting cement to ceramics. Dent Mater 2003; 19: 725-731.

10. Sahafi A, Peutzfeldt A, Asmussen E et al. Effect of surface treatment of prefabricated posts on bonding of resin cement. Operative Dentistry 2004; 29: 60-68.

11. Murahara S, Kajihara H, Hori S et al. Bonding durability of commercially-available luting systems for ceramic restoration to dental zirconia. J Jpn Prosthodont Soc 2007; 51: 733-740.

12. Isgro G, Kleverlaan CJ, Wang $\mathrm{H}$ et al. Thermal dimensional behavior of dental ceramics. Biomaterials $2004 ; 25: 2447-2453$.
13. Miura S, Inagaki R, Yoda M et al. Thermal expansion of layering porcelains for the tetragonal stabilized zirconia. J Jpn Prosthodont Soc 2007; 51: 556-562.

14. Schulte W. Kinematik von enossallen Implanten. Z Zahnarztl Implantol 1989; 5:174-179.

15. Schulte W. Implants and periodontium. Int Dent J 1995; 45: 16-26.

16. Maezawa N, Wakabayashi N, Yokoyama A et al. Influence of intensity of occlusal contact in implant-retained single restoration on stress distributions of crown surface and supporting bone. $\mathrm{J}$ Jpn Prosthodont Soc 2007; 51: 582-591. 